\title{
Caracterização de uma Junta Soldada com Suporte de Solda a Base de Fibra de Vidro
}

\section{(Characterization of aWelded Joint with Fiber Glass Based Weld Support)}

\author{
Luiz Cláudio Soares Tatagiba', Angelus Giuseppe Pereira da Silva², Ronaldo Paranhos ${ }^{2}$ \\ ${ }^{1} E \& P-S E R V / U S-S U B / E Q S B-P E T R O B R A S$. Macaé, RJ, Brasil. \\ ${ }^{2} U E N F-C C T-L A M A V$, Campos dos Goytacazes, RJ, Brasil.paranhos@uenf.br.
}

\begin{abstract}
Resumo
O objetivo deste trabalho foi avaliar um suporte de solda a base de tecido de fibra de vidro, tendo sido usada uma junta soldada pelo processo MIG/MAG de aço C-Mn com $16 \mathrm{~mm}$ de espessura e chanfro tipo V, característico da soldagem unilateral. Após a deposição do passe de raiz sobre o suporte de solda, a junta foi completada por soldagem MIG/MAG convencional, sendo avaliada por meio de ensaios não-destrutivos e destrutivos (tração transversal, dobramento lateral e dureza), além de microscopia óptica e espectrometria de energia dispersiva de raios- $X$ (EDS) nas inclusões do passe de raiz e do passe de acabamento. Os resultados mostram que a microestrutura do metal de solda é semelhante na raiz e no acabamento da junta soldada e típica de metal de solda de aços ferríticos. No passe de raiz, que esteve em contato com o suporte de fibra de vidro, não foi observado contaminação pela fibra de vidro tanto na superficie do cordão de solda como nas inclusões não metálicas. Os resultados dos ensaios mecânicos (tração, dobramento e dureza) foram adequados e mostraram a adequabilidade do suporte de solda a base de fibra de vidro para aplicações na indústria de fabricação por soldagem.
\end{abstract}

Palavras-chave: Soldagem unilateral; Suporte de solda; Fibra de vidro.

Abstract: The objective of this work was to evaluate a weld support based on fiber glass tissue, having been used a joint welded by the MIG/MAG process of an C-Mn steel with $16 \mathrm{~mm}$ thick and a V groove, characteristic of the one-side welding. After the depostition of the root pass over the weld support, the joint was completed by conventional MIG/MAG welding, being evaluated by means of nondestructive and destructive tests (transversal tension, lateral bending and hardness). In addition, optical microscopy and spectroscopy of dispersed energy (SDE) in inclusions of the root pass and the finishing pass. The results show that microsctructure of the weld metal is similar at the root and at the finishing weld bead and typical of ferritic steel weld metal. At he root pass, which was in contact with the fiber glass weld support, there was not observed contamination of fiber glass, both in the bead surface and in the non-mettalic inclusions. The results of mechanical tests (tension, bending and, hardness) were adequate and shown adequability of the fiber glass weld support for the industry of welding manufacturing.

Key words: One-sided welding; Weld support; Fiber glas.

\section{Introdução}

O uso de suporte de solda na soldagem ocorre quando se deseja obter completa penetração da solda em um único passe ou quando o metal base não apresenta massa suficiente para fornecer um adequado anteparo para a poça de solda líquida. A soldagem unilateral com suporte de solda é considerada um processo de alta produtividade $[1,2]$, pois elimina a necessidade de virar a peça para soldar o lado oposto suprime trabalhos extras de preparação na montagem antes da soldagem.

O suporte cerâmico tem sido o mais freqüentemente usado na soldagem do aço [3]. O aspecto rígido e frágil da cerâmica impede que esta se molde adequadamente em alguns tipos de chanfros. Sua aplicação é mais favorável para chanfros retilíneos. Em soldas circunferenciais, apenas diâmetros superiores a 600 mm podem receber o suporte cerâmico articulado. [4].

(Recebido em 28/02/2012; Texto final em 02/03/2012).
Trabalho anterior [5] mostrou a eficiência da fibra de vidro em atuar como suporte da poça de solda. A fibra de vidro apresenta propriedades comuns às cerâmicas [6,7], e testes de soldagem mostraram haver um campo operacional de parâmetros de soldagem que geram cordão da raiz da solda com morfologia adequada e isento de defeitos [5].

O objetivo deste trabalho é avaliar um suporte de solda experimental, à base de camadas de tecido de fibra de vidro sobrepostas na soldagem do passe de raiz. Ensaios nãodestrutivos e destrutivos foram executados, de forma a avaliar a performance do suporte de solda à base de fibra de vidro na soldagem de fabricação de elevada produtividade.

\section{Materiais e Métodos}

O tecido de fibra de vidro usado foi o tipo WR-200 da Texiglass Indústria e Comércio Têxtil, com espessura de 0,21 $\mathrm{mm}$ [8]. O suporte de solda à base de tecido de fibra de vidro, com dimensões de $600 \times 50 \times 3,2 \mathrm{~mm}$ foi confeccionado com 
dez camadas de tecido de fibra de vidro sobrepostas e costuradas em máquina de costura industrial. Para fixação na junta soldada, fita dupla face foi usada, como mostrado na figura 1.

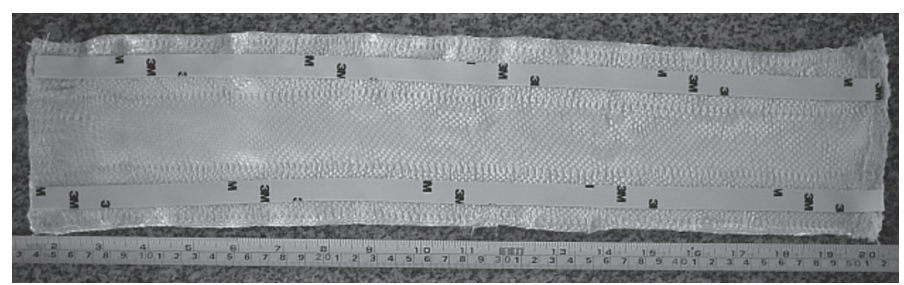

Figura 1. Suporte de solda a base de camadas sobrepostas de tecido de fibra de vidro.
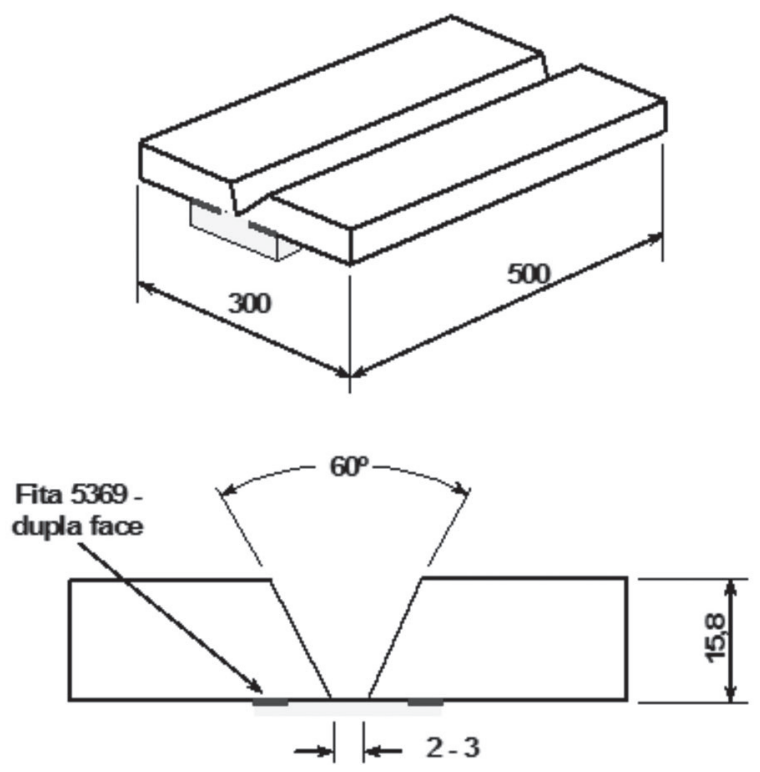

\section{Legencla:}

Tecido WR-200 - 10 camaclas

Fita adesiva dupla face Y-5369

Obs.: dimensões em mm

Figura 2. Desenho esquemático com dimensões da chapa de teste e suporte de solda.

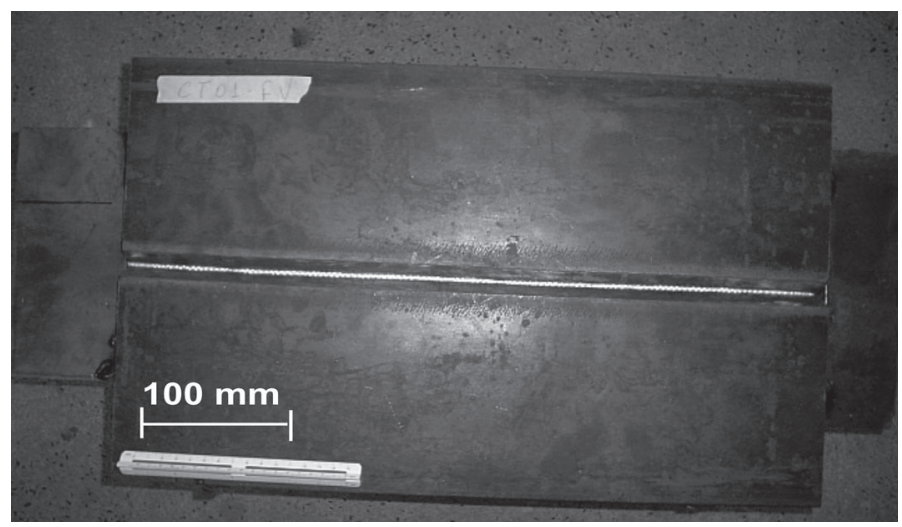

(a)
A soldagem foi executada em uma chapa A-36 com as dimensões 500 X 300 X 15,8 mm e chanfro em V. A figura 2 mostra o desenho esquemático com dimensões da chapa e do suporte de solda utilizado. A figura 3 (a e b) mostra a parte superior e a inferior da chapa de teste montada com o suporte de solda fixado a ela. Dispositivos auxiliares foram usados para fixar a peça. Foi usado o processo GMAW com arame classe ER70S-6 de diâmetro 0,8 mm. A vazão do gás de proteção foi de $15 \mathrm{l} / \mathrm{min}$. A extensão do eletrodo (stickout) variou de 18 a $25 \mathrm{~mm}$. A abertura de raiz foi entre 2,0 e 3,0 $\mathrm{mm}$. Os demais parâmetros e a sequência da soldagem serão apresentados no item resultados e discussão. A soldagem foi executada na posição plana, tendo sido necessários vários passes para completar a junta. No passe de raiz, o soldador aplicou pequena oscilação (trançado) na tocha. Nos passes de enchimento e acabamento esta mesma oscilação foi controlada pelo soldador com a finalidade de se obter um enchimento adequado do chanfro.

Após a soldagem foram realizados ensaios de inspeção visual, líquido penetrante e macrografia, com a finalidade de verificar descontinuidades superficiais e o aspecto da seção transversal da junta soldada.

Ensaio de tração transversal (dois cp's) e dobramento lateral (quatro cp's) foram realizados na junta soldada com o suporte de solda de fibra de vidro. As dimensões, quantidade e a localização de retirada dos corpos de prova de dobramento e tração na chapa de teste, assim como os critérios de aceitação dos ensaios foram de acordo com a norma ASME IX [9].

Dureza vickers com carga de $50 \mathrm{~g}$ foi obtida em 36 pontos: 12 medidas para o metal base (MB), 12 medidas para a zona termicamente afetada (ZTA) e 12 medidas para a zona fundida (ZF). As medições foram feitas a cerca de $1,5 \mathrm{~mm}$ da superfície inferior e superior da junta soldada, como mostrado na figura 4. A finalidade deste ensaio foi a verificação da existência de pontos com dureza elevada na junta soldada com o suporte de solda a base de fibra de vidro. Valores abaixo de 200 Vickers foram considerados como aceitáveis.

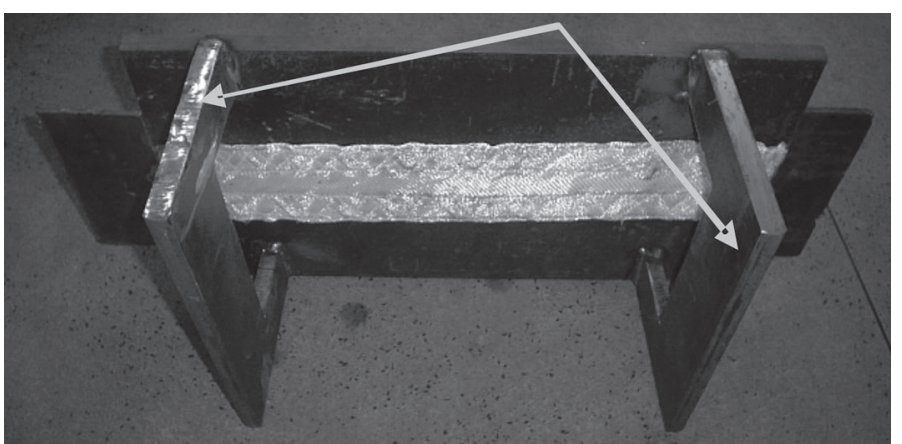

Figura 3. Parte superior (a) e inferior (b) da chapa de teste com suporte de solda fixado 


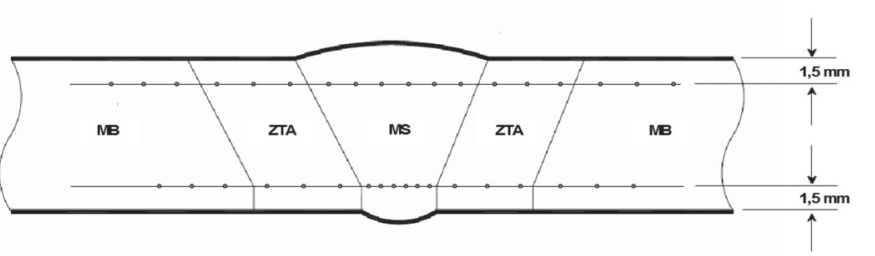

Figura 4. Desenho esquemático com a localização dos pontos para medida da dureza.

Para avaliação da microestrutura por microscopia óptica, foi usada uma seção transversal no centro da junta soldada. A preparação metalográfica usou lixas de granulometria 100, 220, $320,400,600$ e 1200 mesh seguido de polimento com pasta de alumina de $1 \mu \mathrm{m}$ e $0,05 \mu \mathrm{m}$. $\mathrm{O}$ ataque químico da superfície foi com o reagente nital $2 \%$. Teve por objetivo identificar os constituintes da zona fundida, tanto na raiz da solda, onde foi usado o suporte de fibra de vidro, como no cordão de acabamento.

Espectrometria de energia dispersiva de raios-X (EDS) acoplado ao MEV foi usada para análise das inclusões do cordão de solda. Foi usada a amostra para metalografia óptica, porém sem ataque químico. Foi feita uma análise química semiquantitativa de algumas inclusões, tanto no passe de raiz como no passe de acabamento da junta soldada. Esta análise teve a finalidade de verificar uma possível contaminação do material do suporte de fibra de vidro no passe de raiz.

\section{Resultados e Discussão}

O objetivo deste trabalho foi simular uma soldagem unilateral com uso de suporte de solda, semelhante à utilizada na indústria de fabricação por soldagem, sendo esta junta submetida aos ensaios normalmente utilizados para qualificar procedimentos de soldagem. Porém, o suporte de solda é constituido por tecidos de fibra de vidro, cuja eficácia em soldagem foi demonstrada em trabalho publicado previamente [5]

Os parâmetros de soldagem medidos e calculados são mostrados na tabela 1 , sendo que estes encontram-se no interior do campo operacional determinado em trabalho anterior [5]. O tempo de soldagem foi cronometrado para cada cordão de solda aplicado, e a energia de soldagem $(E)$ calculada pela equação $E$ $=(V x A) \times 60) /(1000 \times v)$, onde $V$ é a tensão, $A$ é a corrente e $v$ é a velocidade da soldagem.

Após a soldagem, a superfície do passe de raiz em contato com o suporte de solda de fibra de vidro foi submetida à inspeção visual e por líquido penetrante. Os resultados foram satisfatórios, não tendo sido detectadas descontinuidades. Também não foi verificada nenhuma inclusão do material do suporte à base de tecido de fibra de vidro. A figura 5 mostra a superfície da solda que esteve em contato com o suporte de fibra de vidro durante os ensaios não destrutivos.

Tabela 1. Parâmetros de soldagem medidos e calculados.

\begin{tabular}{|c|c|c|c|c|c|c|}
\hline Passe & Tensão $(V)$ & Corrente $(A)$ & $\begin{array}{c}\text { Corrente média } \\
(A)\end{array}$ & $\begin{array}{c}\text { Tempo de arco } \\
\text { aberto }(\mathrm{min})\end{array}$ & $\begin{array}{c}\text { Velocidade de soldagem } \\
(v)(\mathrm{mm} / \mathrm{min})\end{array}$ & $\begin{array}{c}\text { Energia de soldagem } \\
(E)(\mathrm{kJ} / \mathrm{mm})\end{array}$ \\
\hline 01 & 20 a 22 & 145 a 152 & 149 & 3,00 & 166,67 & 1,13 \\
\hline 02 & 20 a 22 & 139 a 151 & 142 & 4,20 & 119,05 & 1,50 \\
\hline 03 & 20 a 22 & 132 a 145 & 139 & 3,80 & 131,58 & 1,33 \\
\hline 04 & 20 a 22 & 145 a 154 & 150 & 1,83 & 273,22 & 0,69 \\
\hline 05 & 20 a 22 & 139 a 143 & 141 & 1,53 & 326,80 & 0,54 \\
\hline 06 & 20 a 22 & 149 a 158 & 154 & 1,58 & 316,46 & 0,61 \\
\hline
\end{tabular}

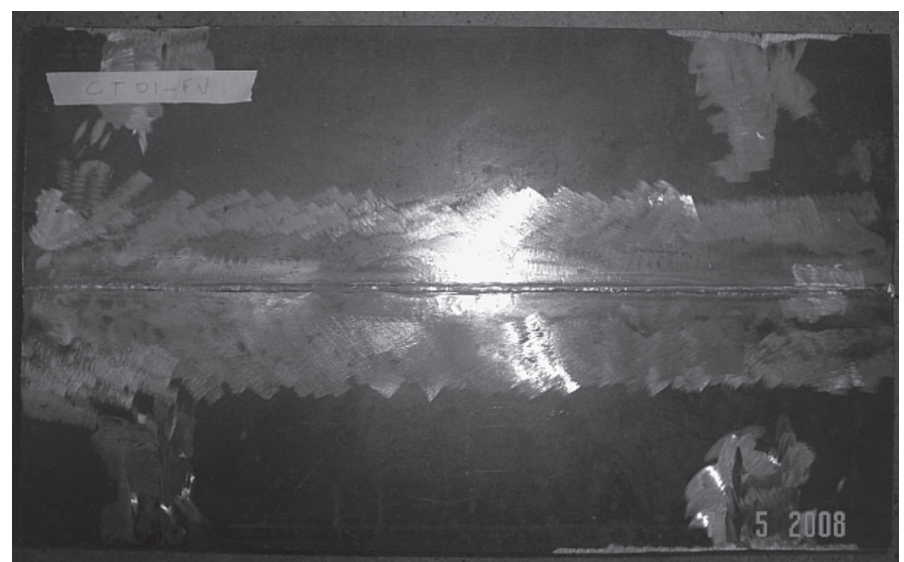

(a)

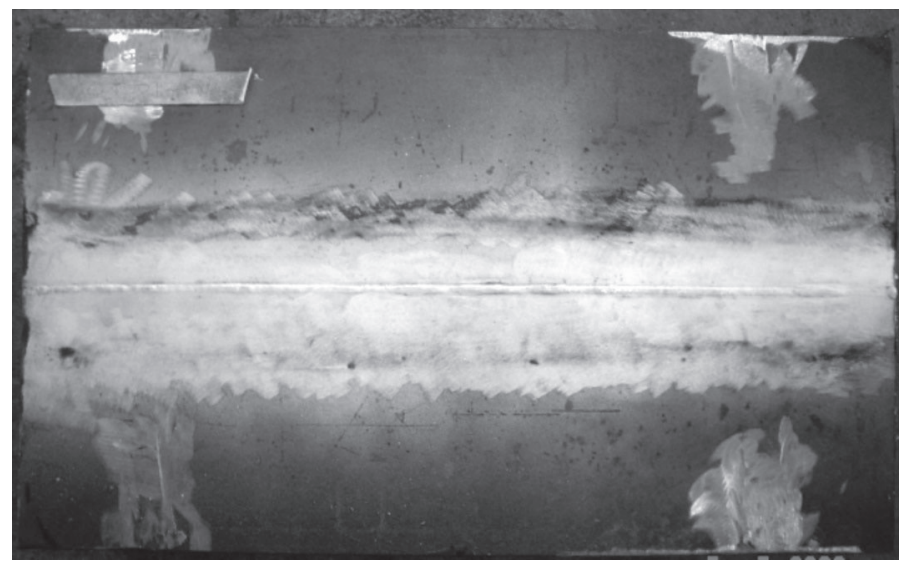

(b)

Figura 5. Inspeção visual e por líquido penetrante da superfície do passe de raiz em contato com o suporte de fibra de vidro. 
A figura 6 mostra a macrografia da seção transversal de uma região central da junta soldada. Pode ser observada a sequência de deposição dos 6 passes de solda, indicando ainda a largura e reforço do passe de raiz. Pode ser observado que houve penetração adequada, tendo sido fundido a base do chanfro em $\mathrm{V}$ e promovendo um reforço de solda de $2,2 \mathrm{~mm}$ na superfície em contato com o suporte de fibra de vidro. A macrografia mostrou um aspecto satisfatório da geometria do passe de raiz, com largura de 7,8 $\mathrm{mm}$, indicando que cerca de 2,6 $\mathrm{mm}$ de cada lado da base do chanfro $\mathrm{V}$ foi fundida na soldagem. Não se observam descontinuidades.

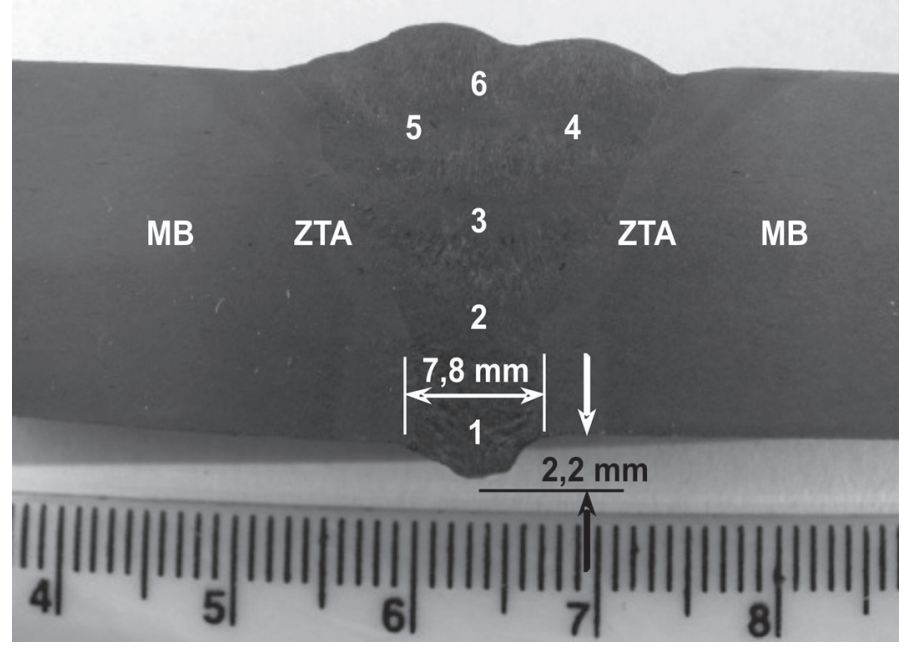

Figura 6. Macrografia da junta soldada, com indicações da largura e altura do reforço. Legenda: 1, 2, 3, 4, 5 e 6 : sequência de passes de solda; MB: Metal de Base; ZTA: Zona Termicamente Afetada

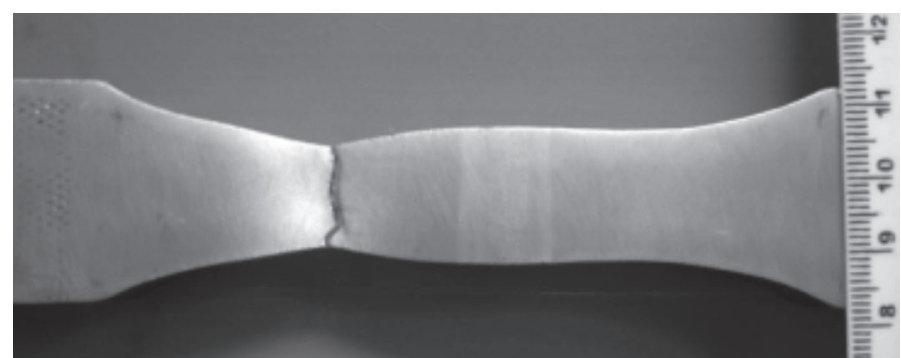

CP-T1

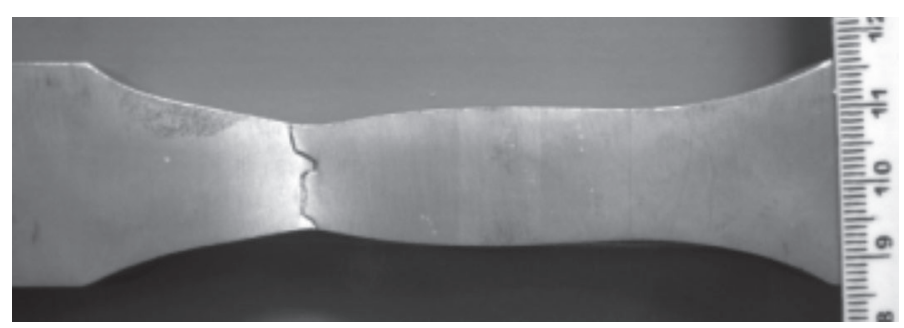

CP-T2

Figura 7. Corpos de prova de tração transversal após ensaio.

A figura 7 mostra os corpos de prova de tração transversal, que romperam no metal de base, com aspecto dúctil. A tabela 2 mostra os valores de tensão de ruptura medido nos ensaios e a faixa de resistência mecânica especificada para o metal de base ASTM A-36 [10]. Os resultados foram considerados aceitáveis, pois a fratura do tipo dúctil ocorreu no metal de base e os valores de tensão de ruptura ficaram entre os limites de aceitação especificados na norma ASME IX [9].

Tabela 2. Resultados do ensaio de tração transversal.

\begin{tabular}{|c|c|c|}
\hline Corpos de prova & $\begin{array}{c}\text { Resistência a } \\
\text { Tração }(\mathrm{MPa})\end{array}$ & Local de ruptura \\
\hline CP-T1 & 444 & Metal de base \\
\hline CP-T2 & 439 & Metal de base \\
\hline \multicolumn{2}{|c|}{ Resistência a tração da chapa ASTM A-36 [10] - 400 a 550 Mpa } \\
\hline
\end{tabular}

Nos ensaios de dobramento lateral, os 4 corpos de prova (figura 8) não apresentaram descontinuidades maiores que 3,0 mm, conforme critério de aceitação da norma ASME IX [9], sendo considerados como aprovados.

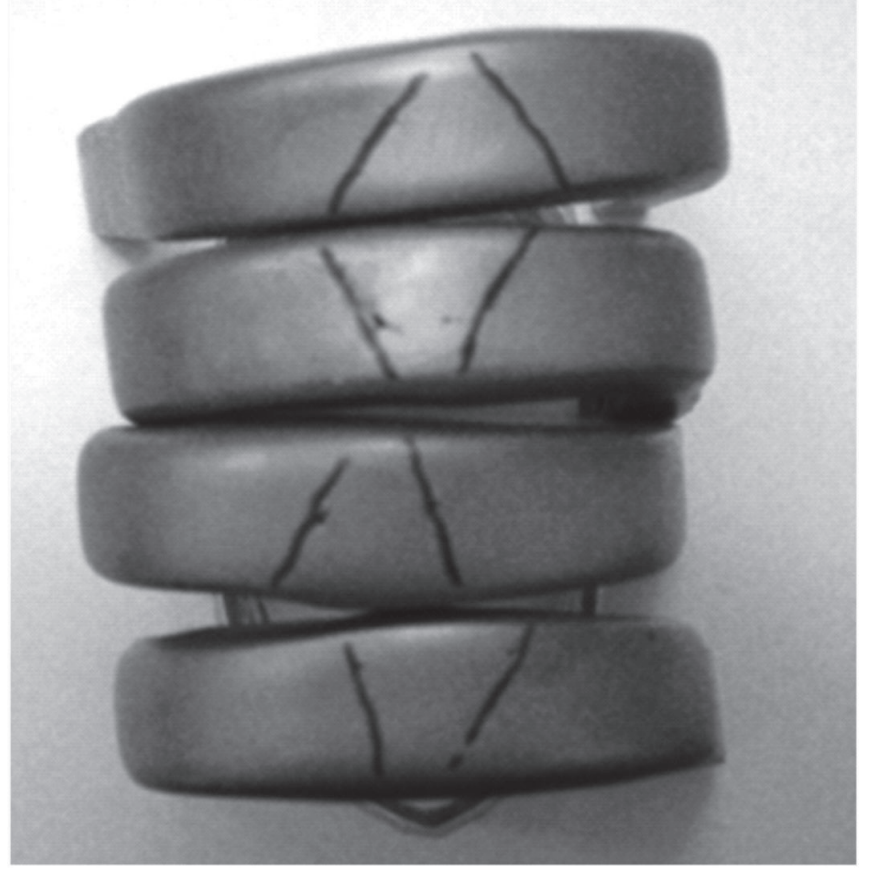

Figura 8. Corpos de prova após o ensaio de dobramento lateral.

Os resultados de dureza vickers são mostrados na tabela 2 . O metal base apresentou média de $157 \mathrm{HV}$ na parte superior e $173 \mathrm{HV}$ na parte inferior. A ZTA apresentou média de $171 \mathrm{HV}$ na parte superior e $150 \mathrm{HV}$ na parte inferior. A zona fundida (ZF) apresentou média de $176 \mathrm{HV}$ nos cordões de acabamento e média de $154 \mathrm{HV}$ no passe de raiz. Os resultados de dureza evidenciam a ausência de pontos duros na junta soldada com a utilização do suporte à base de fibra de vidro, e demonstra que o ciclo térmico da soldagem não produziu um endurecimento significativo nesta região. Os valores de dureza são compatíveis ao aço ferrítico A-36 e ao metal de adição produzido com o arame ER70S-6 utilizado na soldagem MIG/MAG. Estes resultados são similares aos encontrados por Almeida [11,12], onde a soldagem unilateral foi executada com as mesmas variáveis (processo de soldagem, metal de base, metal de adição, etc.), porém com suporte de solda cerâmico. 
Tabela 2. Valores da dureza vickers da junta soldada com carga de 50g.

\begin{tabular}{|c|c|c|c|c|c|}
\hline Região & Pontos & Dureza Vickers $\left(\mathrm{kgf} / \mathrm{mm}^{2}\right)$ & Pontos & Dureza Vickers $\left(\mathrm{kgf} / \mathrm{mm}^{2}\right)$ & Média (kgf/mm2) \\
\hline \multirow{3}{*}{$\begin{array}{l}\text { Metal Base } \\
\text { (superior) }\end{array}$} & 1 & 135 & 16 & 186 & \multirow{3}{*}{157} \\
\hline & 2 & 150 & 17 & 135 & \\
\hline & 3 & 166 & 18 & 169 & \\
\hline \multirow{3}{*}{$\begin{array}{l}\text { Metal Base } \\
\text { (Inferior) }\end{array}$} & 1 & 175 & 16 & 188 & \multirow{3}{*}{173} \\
\hline & 2 & 173 & 17 & 146 & \\
\hline & 3 & 169 & 18 & 187 & \\
\hline \multirow{3}{*}{$\begin{array}{c}\text { ZTA } \\
\text { (Superior) }\end{array}$} & 4 & 150 & 13 & 185 & \multirow{3}{*}{171} \\
\hline & 5 & 171 & 14 & 162 & \\
\hline & 6 & 184 & 15 & 171 & \\
\hline \multirow{3}{*}{$\begin{array}{l}\text { ZTA } \\
\text { (Inferior) }\end{array}$} & 4 & 150 & 13 & 135 & \multirow{3}{*}{150} \\
\hline & 5 & 178 & 14 & 155 & \\
\hline & 6 & 131 & 15 & 153 & \\
\hline \multirow{3}{*}{$\begin{array}{c}\text { ZF } \\
\text { (Superior) }\end{array}$} & 7 & 151 & 10 & 188 & \multirow{3}{*}{176} \\
\hline & 8 & 187 & 11 & 190 & \\
\hline & 9 & 175 & 12 & 165 & \\
\hline \multirow{3}{*}{$\begin{array}{c}\mathrm{ZF} \\
\text { (Inferior) }\end{array}$} & 7 & 143 & 10 & 162 & \multirow{3}{*}{154} \\
\hline & 8 & 146 & 11 & 146 & \\
\hline & 9 & 136 & 12 & 189 & \\
\hline
\end{tabular}

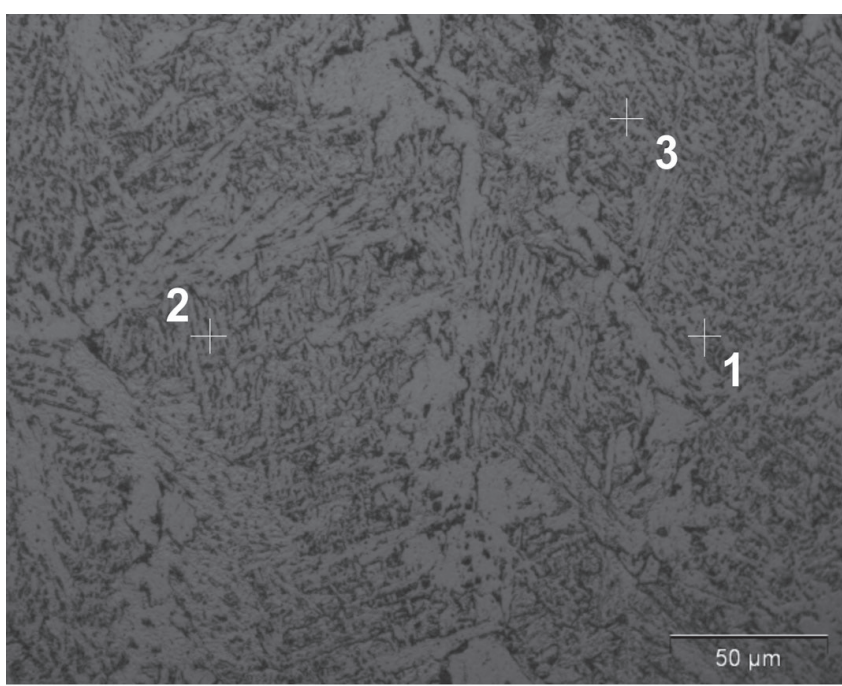

(a)

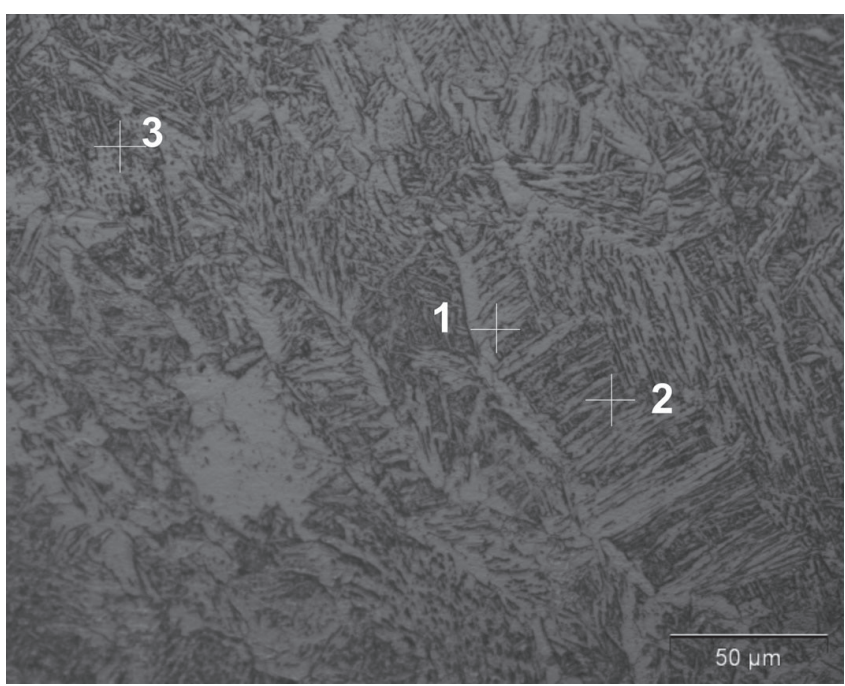

(b)

Figura 9. Micrografia da seção transversal da junta soldada com aumento de 500X (a) Raiz da junta soldada (b) Acabamento da junta soldada. Notação: 1- PF(G), 2- FS(A) e 3- AF

A microestrutura do passe de raiz soldado com suporte à base de tecido de fibra de vidro e do passe de acabamento é mostrada na figura 9. Em ambas as regiões no metal de solda foi observado uma quantidade significativa de ferrita de contorno de grão $(\mathrm{PF}(\mathrm{G}))$ e de ferrita com segunda fase alinhada (FS(A)). A ferrita acicular (AF) aparece em quantidade bem menor quando comparado aos constituintes citados anteriormente. Não foi observada evidência da presença de martensita (M) e de agregado ferrita-carbeto (FC). Nas duas regiões as estruturas são semelhantes e típicas de metal de solda de aços ferríticos $[13,14]$. A microestrutura obtida está coerente com os resultados de dureza mostrados na tabela 2 e de acordo com experimentos citados por Irikura [15], cuja dureza vickers (HV) no metal de solda variou de 153 a $197 \mathrm{HV}$.

As inclusões do metal de solda no passe de raiz (que esteve em contato com o suporte de fibra de vidro) e no passe de acabamento foram analisadas por espectrometria de energia dispersiva de raios-X (EDS) acoplado ao MEV, figuras 10 e 11. Foram observadas inclusões globulares no metal de solda, com tamanhos variados, tanto no passe de raiz como no passe de acabamento. As figuras 10 e 11 mostram, com aumento de $500 \mathrm{X}$, as inclusões não metálicas na raiz e no acabamento da junta soldada, onde foram realizadas micro-análises EDS. Os resultados do EDS em \% peso dos elementos detectados 
nas inclusões não metálicas do passe de raiz e do passe de acabamento são mostrados na tabela 3 e a figura 12 mostra os gráficos típicos destas análises.

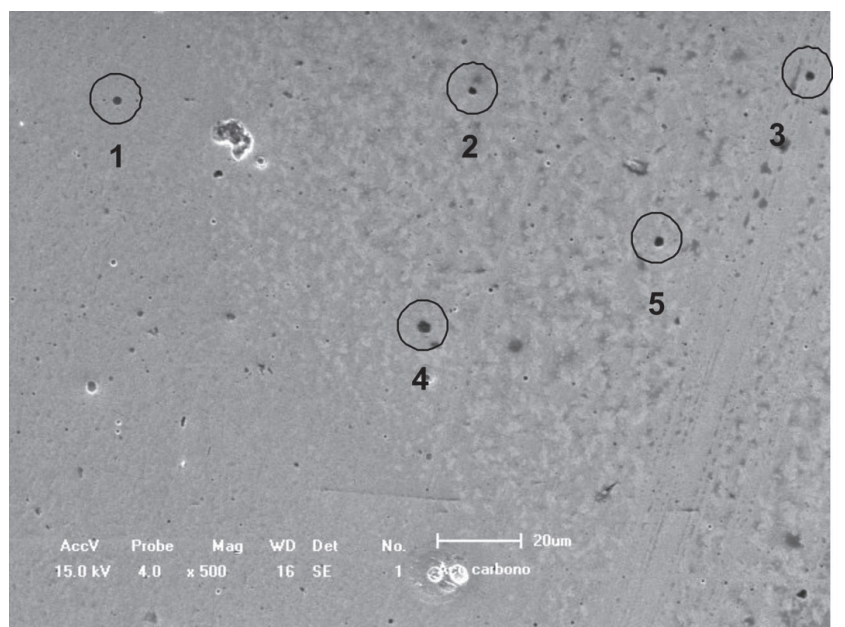

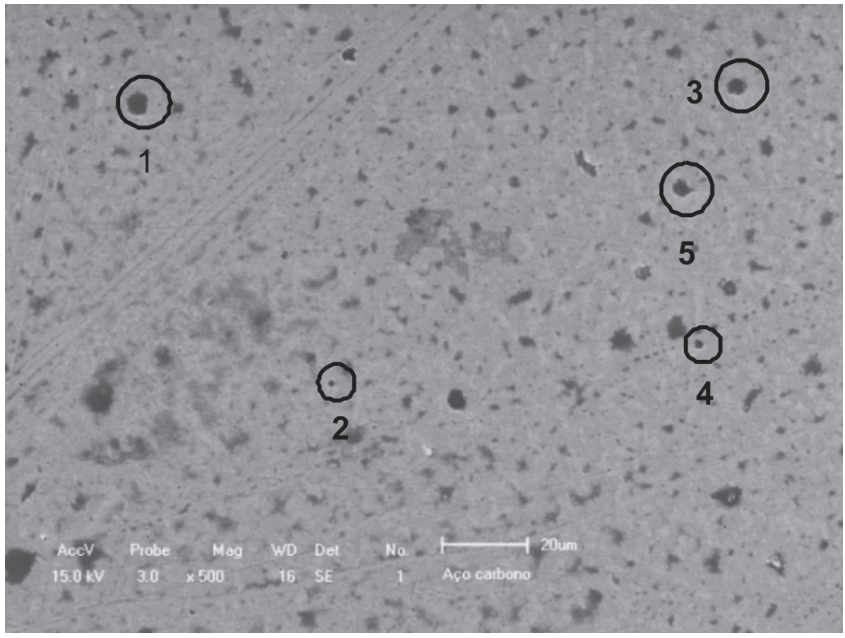

Figura 11. Imagem do MEV sem ataque químico com aumento de 500X - acabamento

Figura 10. Imagem do MEV sem ataque químico com aumento de $500 X$ - raiz

\begin{tabular}{|c|c|c|c|c|c|}
\hline \multicolumn{6}{|c|}{ Raiz } \\
\hline \multirow{2}{*}{ Inclusões (Figura 10) } & \multicolumn{5}{|c|}{ Elementos } \\
\hline & $\mathrm{C}$ & $\mathrm{O}$ & $\mathrm{Al}$ & $\mathrm{Si}$ & $\mathrm{Fe}$ \\
\hline 1 & 10,821 & 45,421 & 16,721 & - & 27,037 \\
\hline 2 & 13,341 & 26,933 & 11,939 & 1,372 & 40,447 \\
\hline 3 & 6,682 & 40,998 & 4,262 & 12,014 & 17,152 \\
\hline 4 & 12,044 & 22,809 & 6,215 & 2,344 & 54,220 \\
\hline 5 & 12,550 & 37,166 & 15,299 & 2,383 & 30,611 \\
\hline Média & 11,088 & 34,665 & 10,887 & 3,623 & 33,893 \\
\hline \multicolumn{6}{|c|}{ Acabamento } \\
\hline \multirow{2}{*}{ Inclusões (Figura 11) } & \multicolumn{5}{|c|}{ Elementos } \\
\hline & $\mathrm{C}$ & $\mathrm{O}$ & $\mathrm{Al}$ & $\mathrm{Si}$ & $\mathrm{Fe}$ \\
\hline 1 & 7,711 & 38,124 & 6,913 & 9,125 & 35,924 \\
\hline 2 & 11,474 & 33,671 & 11,215 & 5,194 & 35,666 \\
\hline 3 & 10,948 & 34,460 & 14,337 & 2,318 & 36,401 \\
\hline 4 & 9,681 & 39,986 & 15,134 & 3,664 & 28,517 \\
\hline 5 & 6,661 & 44,344 & 20,905 & 2,819 & 23,861 \\
\hline Média & 9,295 & 38,117 & 13,701 & 4,624 & 32,074 \\
\hline
\end{tabular}

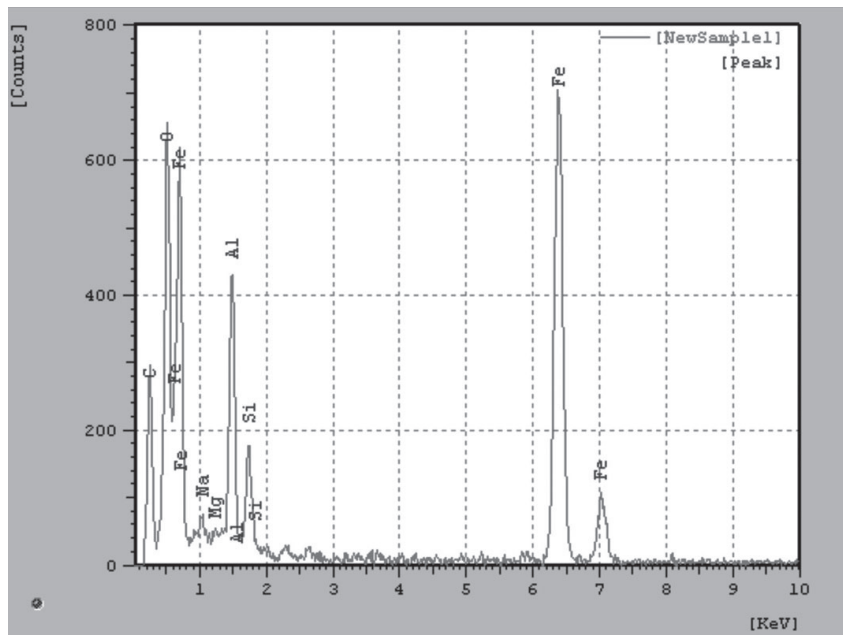

(a)

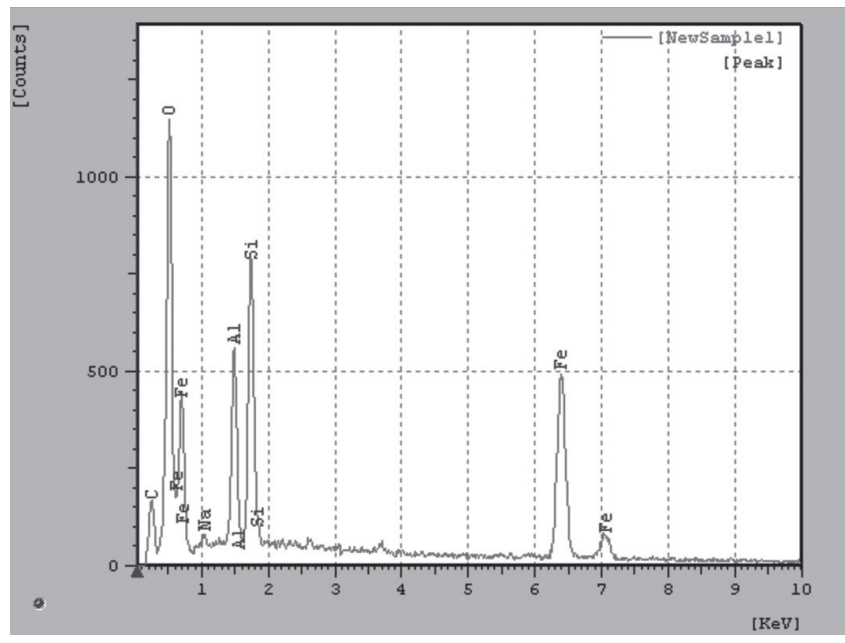

(b)

Figura 12. EDS típico das inclusões do passe de raiz (a) e do passe de acabamento (b) da junta soldada 
A composição média, em \% peso, nas cinco inclusões da raiz analisadas foi de $34,665 \% \mathrm{O}, 33,893 \% \mathrm{Fe}, 11,088 \% \mathrm{C}, 10,887 \%$ $\mathrm{Al}, 3,623 \% \mathrm{Si}$. Para o acabamento a composição média foi de 38,117\% O, 32,074\% Fe, 13,701\% Al, 9,295\% C, 4,624\% Si. As micro-análises EDS realizadas mostraram que a composição média das inclusões do passe de raiz e do ultimo passe de solda apresentam $\%$ peso próximas.

Estes resultados indicam que a complexidade da natureza química das inclusões verificadas está em conformidade com os relatos da literatura $([16,17]$. Os elementos encontrados na composição da inclusão do passe de raiz e do passe de acabamento não são relacionados com a constituição do tecido de fibra de vidro. Durante a solidificação do metal fundido, o oxigênio em excesso é rejeitado da solução e associa-se com os elementos manganês, silício, alumínio, etc. presentes no metal de base e no metal de solda em forma de inclusões. Abson [16] cita ainda que a quantidade de inclusões é afetada essencialmente pela composição química, particularmente do oxigênio em solução no metal fundido.

O silício tem percentual baixo e disperso (1,372 a 12,014\%), que foi atribuído à presença deste elemento químico na poça de fusão, proveniente do metal de adição que age como desoxidante. Quando a concentração de oxigênio é alta e a de silício é baixa na poça de solda o composto $\mathrm{FeO}-\mathrm{SiO} 2$ pode ser formado, sendo o comportamento do alumínio também atribuído ao mesmo motivo [18]. Pode-se então concluir que não houve contaminação do material do suporte à base de tecido de fibra de vidro no passe de raiz da junta soldada. Os resultados aqui apresentados mostram concordância com os resultados das micro-análises EDS do trabalho de Almeida [11], onde foi utilizado suporte cerâmico convencional para soldagem unilateral.

\section{Conclusões}

O estudo realizado neste trabalho, sobre a caracterização de junta soldada com suporte de solda a base de fibra de vidro, pode-se concluir que:

$\mathrm{O}$ suporte de solda à base de fibra de vidro mostrou ser eficiente para suportar a poça de fusão no passe de raiz. Não houve formação de gases durante a soldagem.

A macrografia da seção transversal mostrou que houve penetração nas laterais do chanfro, produzindo largura, reforço e penetração adequados no passe de raiz, não tendo sido observadas descontinuidades.

A microestrutura do metal de solda é semelhante no passe de raiz e no de acabamento da junta soldada, típica do metal de solda de aços ferríticos.

Não foi observada contaminação da fibra de vidro tanto por adesão à superfície do cordão de solda como nas inclusões não metálicas.

Os resultados adequados de resistência à tração, dobramento e dureza mostraram a eficiência do suporte à base de tecido de fibra de vidro para aplicações na indústria de fabricação por soldagem.

\section{Agradecimentos}

Os autores agradecem ao CNPq por auxílios concedidos.

\section{Referências Bibliográficas}

[1] MUIR, J. Single side panel welding with ceramic tile backing, Metal Construction, p.651-653, Oct. 1985.

[2] JUNIOR, R. C. Soldagem com Backings Cerâmicos. In: Revista Solução ESAB, n. ${ }^{\circ}$ 11, p 55-62. 2009.

[3] PARANHOS, R. P. R., SOUZA, A. C. "Soldagem a Arco Submerso". Coleção Soldagem 2000. Rio de Janeiro. FIRJAN 1 SENAI, 87 p.1999.

[4] XIANGSHAN WELDING BACKING FACTORY.

Catálogo de produtos. Welding Backing Factory; <http://www. chinabacking.com/en/products.php em 23/04/2007.

[5] TATAGIBA, L.C., SILVA, A.G.P., PARANHOS, R.P.R. Investigação sobre a Eficiência da Fibra de Vidro e da Fibra Cerâmica como Suporte de Solda na Soldagem Unilateral. Soldag. Insp. São Paulo, Vol.16, No. 4, p.377-386, Out/Dez 2011.

[6] CALLISTER JR., W. D. Ciência e Engenharia de Materiais: Uma Introdução. LTC Editora. 589 p. 2002.

[7] CHAWLA, K. K. Ceramic Matrix Composites. London. Chapman \& Hall. 415 p. 1993.

[8] TEXIGLASS. Ficha técnica de tecidos. São Paulo.

Maxepoxi Industrial e Comercial Ltda.; em http://www.

maxepoxi.com.br/tecnica tecidos.asp em 03/06/2007.

[9] ASME IX. American Society of Mechanical Engineers - Boiler \& Pressure Vessel Code. Qualification Standard for Welding and Brazing Procedures, Welders, Brazers, and Welding and Brazing Operators. New York, USA. 2004.

[10] ASTM A36. American Society For Testing And Materials. Standard Specification for Carbon Structural Steel. Copyright @ ASTM International. United States of America. 2008.

[11] ALMEIDA, L.L.P. Desenvolvimento de Suporte Cerâmico para Aplicação em Soldas Unilaterais com Elevada Produtividade. Tese (Mestrado em Engenharia e Ciências dos Materiais) - Campos dos Goytacazes - RJ, Universidade Estadual do Norte Fluminense Darcy Ribeiro - UENF, 127p. 2008.

[12] ALMEIDA, L.L.P., TATAGIBA, L.C.S., ROCHA, J.P., BASTOS, L.R., RIBEIRO, P.C., PARANHOS, R.P.R. Avaliação da Junta Soldada com Suporte Cerâmico a Base do Mineral Refratário Cordierita. Anais do $5^{\circ} \mathrm{COBEF}-$ Congresso Brasileiro de Engenharia de Fabricação - Seleção de Soldagem, BH, MG, Brasil. 2009.

[13] DOLBY, R.E. Guidelines For Classification Of Ferritic Steel Weld Metal Microstructural Constituents Using The Light Microscope. Welding In The World, Vol. 24, No 7/8, Pp. 144148. 1986.

[14] FONSECA, A.S.M., ALMEIDA, A.L.S., RIOS, P.R. Análise Comparativa Ponto A Ponto Da Quantificação Da Microestrutura Do Metal De Solda Segundo O Método Do IIW. Anais Encontro Nacional De Tecnologia Da Soldagem, 18, P. $513-522.1992$.

[15] IRIKURA S.I.; HIRAYAMA, R.; TOKIMATSU, R.C.; 
VENTRELLA, V.A.; GALLEGO, J.; YAMAKAMI, W.J. Análise Microestrutural de uma Junta Soldada - Microdureza e Fração Volumétrica. , Anais do $17^{\circ} \mathrm{CBECIMat} \mathrm{-} \mathrm{Congresso}$ Brasileiro de Engenharia e Ciência dos Materiais, Foz do Iguaçu, PR, Brasil, p. 5036 a 5047. 2006.

[16] ABSON, D. J. Non-metallic inclusions in ferritic steel weld metals - a review. Welding in the World, v. 27, n. 3/4, pp. 76101. 1989.

[17] BYUN, J.S.; SHIM, J.H.; CHO, Y.M.; LEE, D.N. Nonmetallic inclusion and intragranular nucleation of ferrite in Tikilled C-Mn steel. Acta Materialia, v. 51, pp. 1593-1606. 2003.

[18] LIU, S.; OLSON, D.L. The Influence of Inclusion Chemical Composition on Weld Metal Microstructure. J. Materials Engineering, Vol. 9, No. 3, pp. 237-251. 1987. 